\title{
Mechanical Bowel Preparation for Elective Colorectal Surgery: Is It Enough? Reply
}

\author{
George Peppas • Vangelis G. Alexiou • \\ Matthew E. Falagas
}

Received: 14 April 2009/Accepted: 15 April 2009/Published online: 9 May 2009

(C) 2009 The Society for Surgery of the Alimentary Tract

\section{Dear Editor,}

We would like to thank Drs. Gravante and Caruso for sharing their thoughts and updated systematic review on this important issue.

We do agree that mechanical bowel preparation/cleansing (MBP) may cause fluid and electrolyte abnormalities. This may be anticipated and corrected, but still, given the available evidence from randomized controlled trials (RCTs), it is preferable to avoid mechanical cleansing. Regarding the heterogeneity of RCTs, it should be acknowledged that the methodology of modern RCTs assures that treatment and control groups are stratified for most characteristics including antimicrobial and MBP regimens.

It is rational to believe that, in particular, colorectal surgical procedures with a high probability of anastomotic leakage, MBP may be useful. Specifically, all procedures with rectal location of the disease (e.g., low anterior resection with total mesorectal excision for rectal cancer) that require more distal anastomoses may have a higher probability of anastomotic leakage. However, we believe that recommendations should be based on evidence and not only medical reasoning. RCTs that stratified the risk of leakage to the site of anastomosis did not find any significant advantage of MBP for surgical procedures with rectal location of the disease. ${ }^{1-3}$ As stated in our article, ${ }^{4}$ we are confident that current literature provides strong evidence that in elective colorectal surgery, no significant benefit is derived from MBP. This applies to all procedures regardless of the site of anastomosis. Still, we agree that future well-conducted RCTs that are stratified for specific surgical procedures will add further evidence to support more specific recommendations.

\section{References}

1. Miettinen RP, Laitinen ST, Mäkelä JT, Pääkkönen ME. Bowel preparation with oral polyethylene glycol electrolyte solution vs. no preparation in elective open colorectal surgery: prospective, randomized study. Dis Colon Rectum. 2000;43:669-675. doi:10.1007/BF02235585.

2. Ram E, Sherman Y, Weil R, Vishne T, Kravarusic D, Dreznik Z. Is mechanical bowel preparation mandatory for elective colon surgery? A prospective randomized study. Arch Surg. 2005;140:285-288. doi:10.1001/archsurg.140.3.285.

3. Fa-Si-Oen P, Roumen R, Buitenweg J, van de Velde C, van Geldere $\mathrm{D}$, Putter H, et al. Mechanical bowel preparation or not? Outcome of a multicenter, randomized trial in elective open colon surgery. Dis Colon Rectum. 2005;48:1509-1516. doi:10.1007/s10350-0050068-y.

4. Peppas G, Alexiou VG, Falagas ME. Bowel cleansing before bowel surgery: major discordance between evidence and practice. J Gastrointest Surg 2008;12:919-920. 